\title{
ANÁLISE ESTRUTURAL ESTÁTICA E OTIMIZAÇÃO GEOMÉTRICA: CONSIDERAÇÕES DA MECÂNICA DOS SÓLIDOS E TOMOGRAFIA VIRTUAL, APLICADA A UM PARA- CHOQUE FRONTAL VEICULAR
}

\author{
Márcio Lucas Ignácio Costa ${ }^{1}$ e Roderlei Camargo ${ }^{1}$ \\ ${ }^{1}$ UNISAL, Centro Universitário Salesiano de São Paulo \\ E-mails: marciolucas22@gmail.com, roderlei.camargo@sj.unisal.br
}

\section{RESUMO}

O para-choque frontal consiste em uma estrutura composta por uma carenagem, e uma viga de proteção, conectada a estrutura do automóvel, sendo que as duas partes, possuem basicamente a mesma finalidade. A única diferença é que a carenagem, também possui a finalidade estética, porém, ambas possuem como finalidade principal, o objetivo de absorver a energia gerada por impactos a uma baixa velocidade. Este objetivo principal, consta de três propósitos, em que os dois últimos descritos, possuem maior relevância: o primeiro é proteger as partes mecânicas do automóvel, o segundo é proteger os passageiros e o condutor, e o terceiro é prevenir danos ao pedestre em caso de atropelamento menores. Neste sentido, apresenta-se neste trabalho, um estudo de analise estrutural de uma viga de para-choque frontal veicular, confeccionado em Alumínio AL-6061, com espessura de $3 \mathrm{~mm}$. A montagem se dá em conjunto com uma espuma confeccionada em polímero expandido, cuja finalidade principal é a de absorver o impacto. A técnica de modelamento, seguida de simulação computacional é a FEA (Finite Element Analysis), em que se obtém os resultados de deslocamento $(\Delta l)$ e de tensão $(\sigma)$, a partir de um modelo matemático submetido a uma velocidade de 30 $\mathrm{km} / \mathrm{h}$. Considerou-se o peso veicular de $1500 \mathrm{~kg}$, sendo a analise conduzida dentro do intervalo de validação da lei de Hooke. Assim, os resultados matemáticos obtidos, foram correlacionados entre as duas analises, modelo base e modelo otimizado, indicando a melhoria na absorção do impacto, tendo também como referência, a tomografia virtual oriunda da simulação.

\section{INTRODUÇÃO}

O conceito de projetar automóveis cada vez mais seguros para a sociedade, não apenas aos integrantes do veículo, mas também para as pessoas ao seu redor, é uma ideia extremamente relevante. Pois, proporciona maior segurança aos pedestres, e é como dizer que as vítimas de atropelamentos, teriam lesões menores e com isto, menores riscos de mortes. Desta forma, a consequência seria a redução do número de óbitos, causados por atropelamento veicular.

Em 2013, os dados da OMS (Organização Mundial da Saúde) apontaram que mais de 270.000 pedestres, morreram envolvidos em acidentes de transito, por ano. Sendo que $22 \%$ do total de fatalidades envolvidas nos acidentes [1], são creditadas 
a estas causas. Por este motivo, a comissão européia (DG_Enterprise and Industry, Sustainable Mobility and Automotive Industry Unit) solicitou um estudo ao TRL (Transport Research Laboratory of the UK), com a finalidade de investigar a causa raiz destes acidentes, assim como, prever as ações necessárias a um plano de contingencia, que minimizasse estes traumas.

Este estudo trata de recolher informações que pudessem ser incorporadas na Regulamentação de Segurança Geral (General Safety Regulation) e Legislação de Segurança do Pedestre (Pedestrian Safety Legislation) [2], com a finalidade de promover novas regras nesse segmento.

Devido a estes números, algumas legislações foram criadas intencionalmente para solucionar esse problema e assim, muitas ideias vêm sendo desenvolvidas e aplicadas neste segmento.

Atualmente, essas legislações só existem na Europa, e em alguns outros países mais desenvolvidos, motivo pelo qual algumas destas ideias, somente são aplicadas nestas regiões.

Porém, existe uma tendência que em uma data próxima, essas legislações também sejam implementadas na américa latina, assim, as montadoras nacionais serão obrigadas a aplicarem estes sistemas em seus veículos. Mas, diante de um número exacerbado de pedestres envolvidos em acidentes, mesmo que estas legislações levem alguns anos para serem implantadas, acredita-se que esse já seja um motivo mais do que pertinente para analise, desenvolvimento e aplicação de um sistema, ligado a este segmento de segurança.

Para fundamentar este estudo, está sendo levado em consideração, ideias já implementadas na região europeia, onde as regras de segurança já se aplicam. Pesquisas deste segmento, vêm sendo realizadas desde a década de 1930, por intermédio de métodos experimentais [3], e depois da década de 1980, com o desenvolvimento do computador, estas pesquisas mudaram para o método numérico, mais propriamente, o método de elementos finitos [4]. Tornando-se assim, o principal método de pesquisa e desenvolvimento baseado em colisões veiculares.

Para obter a solução e ter um parâmetro de referência, inicialmente foi construído um modelo 3D de para-choque, tendo como base um modelo de carro europeu, conforme Figura 1. Foi considerado um perfil similar ao original, confeccionado em alumínio AL-6061 e montado juntamente com uma barra de espuma de polímero expandido. Em seguida, foi realizada uma análise FEA com o software CREO simulate 2.0, com o escopo de analisar o para-choque veicular, junto a outro material polimérico expandido, para fins de absorção de força de impacto. Esta força foi da ordem de $1183,5 \mathrm{~kg}$, - decorrente da energia de impacto entre um carro de $1500 \mathrm{~kg}$, trafegando a $30 \mathrm{~km} / \mathrm{h}$ e um pedestre de $70 \mathrm{~kg}$ de peso, em estado estacionário - que será distribuída em dois pontos: Central e Lateral.

Desta forma, conseguiu-se representar de forma virtual, a severidade de um impacto, simulando as condições reais para subsequentemente, executar a otimização geométrica correlata. 
A Figura 1 ilustra o modelo de para-choque veicular, utilizado como referência para o estudo de caso, o qual posteriormente, será objeto de otimização geométrica.

Figura 1 - Modelo de para-choque usado como referência

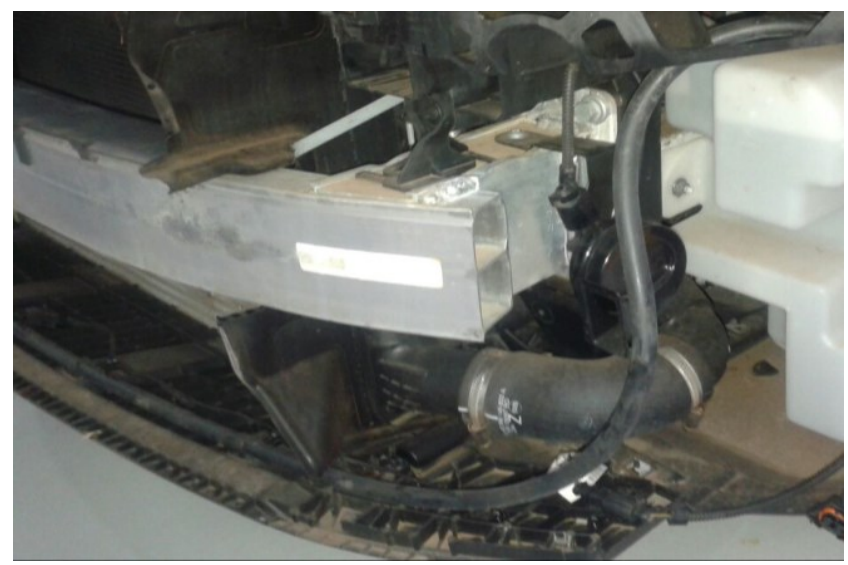

Fonte: Acervo do autor

\section{INFORMAÇÔES GERAIS}

Para se desenvolver produtos inovadores e bem-sucedidos no atual cenário global e competitivo, há que ter recursos de informática cientifica e fazer uso de simulação. Neste senso, para que a empresa sobreviva neste ambiente de competição, a simulação deve fazer parte do projeto, já na fase inicial do processo de desenvolvimento do produto [5], [6]. A capacidade de analisar as características multicorpos do desempenho físico de um produto, antes de se criar um primeiro protótipo, pode aumentar de forma significativa a vida útil do mesmo em campo. As empresas precisam de ferramentas de simulação, robustas o suficiente para superar com eficácia, as demandas de prazo, custo e qualidade final do produto [7]. A tecnologia de simulação, permite a utilização de modelagem matemática, baseada em computador, para aproximar e simular os fenômenos complexos do universo físico, tendo como dados de entrada o modelo CAD 3D [8].

Assim, juntamente com a construção do modelo matemático CAD, formulou-se um equacionamento matemático para o cálculo da força de impacto, gerada entre o pedestre e o veículo. Depois de efetuado o calculo, o valor obtido foi utilizado na analise estrutural via formulação FEA, dentro do ambiente CAE. Após sucessivas iterações e analises de resultados entre os ambientes CAD/CAE, chegou-se a um modelo 3D que mais se adequasse as expectativas. Visto isto, as conclusões e desdobramentos estão destacados em detalhes no capitulo do estudo de caso.

\section{METODOLOGIA}

Neste trabalho, utilizou-se a metodologia FEA seguida de otimização geométrica, visando a melhoria na absorção do impacto. O espectro da análise e síntese do modelo matemático 3D, será obtido via pacote de simulações do módulo CREO Simulate. Este software de CAE utiliza modelos digitais 3D para simular fenômenos físicos reais, via métodos numéricos convergentes, e realizações de cálculos estruturais e seus deslocamentos correlatos. 
Assim, três etapas complementam este método: Input, Solver e Output [9]. Na fase de Input, são considerados os seguintes requisitos: Geometria, Material, Forças aplicadas, Restrições, Propriedades físicas e Elementos. $\mathrm{Na}$ fase de Solver, considera-se o critério do método "P", cuja polinomial pode atingir até o $9^{\circ} \mathrm{grau}$. $\mathrm{Na}$ fase de Output, consideram-se os resultados: Tensão, Deslocamento, Deformação e Tomografia virtual, evidenciando as iso surfaces. Neste momento, a intenção é convalidar estes resultados no intervalo de validação da lei de Hooke, especificamente mantendo o componente na região elástica do diagrama "Tensão $\mathrm{x}$ Deformação" [10].

\section{FUNDAMENTAÇÂO TEÓRICA}

\subsection{Equação da Força de Impacto}

Com a necessidade de saber a amplitude da força gerada no impacto, levou-se em consideração, que o mesmo pode ser descrito matematicamente, pelo emprego das leis do movimento e das leis físicas, que regem o impacto em si. O estudo desta equação, teve como base o trabalho RECHNITZER [11] e formalizado pela FEM (faculdade de engenharia mecânica) da UNICAMP [12], onde foi levado em consideração, um choque frontal do veiculo e um pedestre, considerando este último, como um corpo rígido e estacionário.

Assim, tem-se:

$\mathrm{s}=$ deformação total do veiculo $(\mathrm{m})$

$\mathrm{m}_{1}=$ massa do pedestre $(\mathrm{kg})$

$\mathrm{m}_{2}=$ massa do veiculo $(\mathrm{kg})$

$\mathrm{V}_{1}=$ velocidade do pedestre antes do impacto (nula) (m/s)

$\mathrm{v}_{2}=$ velocidade do automóvel antes do impacto $(\mathrm{m} / \mathrm{s})$

$\mathrm{V}_{3}=$ velocidade pós impacto $(\mathrm{m} / \mathrm{s})$

$\mathrm{v}_{\mathrm{a}}=$ velocidade de aproximação dos corpos $=\mathrm{v}_{1}+\mathrm{v}_{2}(\mathrm{~m} / \mathrm{s})$

$\mathrm{F}=$ força média agindo nos dois corpos durante o impacto $(\mathrm{N})$

$E=$ energia cinética $(J)$

Conservação da quantidade de movimento

$$
\begin{aligned}
& m_{1} v_{1}+m_{2} v_{2}=\left(m_{1}+m_{2}\right) v_{3} \\
& v_{3}=\left(m_{1} v_{1}+m_{2} v_{2}\right) /\left(m_{1}+m_{2}\right)
\end{aligned}
$$

Energia cinética dos dois corpos antes do impacto

$$
E_{0}=0.5\left(m_{1} v_{1}^{2}+m_{2} v_{2}^{2}\right)
$$

Energia cinética após o impacto

$$
E_{1}=0.5\left(m_{1}+m_{2}\right) v_{3}^{2}
$$


Perda da energia no impacto (energia perdida durante a colisão)

$$
\Delta \mathrm{E}=\mathrm{E}_{0}-\mathrm{E}_{1}=\frac{m_{1} m_{2}}{2\left(m_{1}+m_{2}\right)}\left(v_{1}+v_{2}\right)^{2}
$$

Substituindo a velocidade relativa de aproximação entre os corpos $v_{a}=v_{1}+v_{2}$

$$
\Delta \mathrm{E}=\mathrm{E}_{0}-\mathrm{E}_{1}=\frac{m_{1} m_{2}}{2\left(m_{1}+m_{2}\right)}\left(v_{a}\right)^{2}
$$

Força média " $F$ " agindo entre os corpos para uma dada deformação "s"

Levando em consideração que o trabalho realizado pela força "F" (Fs) é igual a energia perdida no impacto

$$
\begin{aligned}
& \mathrm{Fs}=\mathrm{DE}=\mathrm{E}_{1}-\mathrm{E}_{2} \\
& \mathrm{~F}=\frac{\Delta \mathrm{E}}{\mathrm{s}} \rightarrow \Delta \mathrm{E}=\mathrm{F} \mathrm{s}
\end{aligned}
$$

Substituindo (8) em (6)

$$
\mathrm{F}=\frac{m_{1} m_{2} v_{a}^{2}}{2\left(m_{1}+m_{2}\right) s}
$$

Assim, considerando que nesta situação, o veículo sofre uma deformação "s" de $0,2 \mathrm{~m}$, - baseando-se em dados de crash test de impacto, centrado contra uma barreira rígida, e que se comparado ao estudo atual, se trata de um atropelamento [11], e também que o veículo trafegue a uma velocidade máxima de $30 \mathrm{~km} / \mathrm{h}$ [13], que é a velocidade permitida nas vias locais, e que sua massa seja de $1500 \mathrm{~kg}$, e que o pedestre se encontra em estado estacionário $(\mathrm{v}=0 \mathrm{~km} / \mathrm{h})$, sua massa seja de $70 \mathrm{~kg}$, obtém-se que a força de impacto será de $1183,49 \mathrm{~kg}$.

\subsection{Equação da Análise Estática}

A fim de comprovar a eficácia do aplicativo tridimensional, e visando prever uma possível falha de função, a teoria matemática a ser comprovada é: $E=\sigma / \varepsilon$, no limite da fase elástica, considerando-se o coeficiente de segurança. A resposta da estrutura as solicitações virtuais, serão expressas em tensões de Von Mises (MPa) e Displacement $(\mathrm{mm})$, seguida da otimização geométrica do conjunto montado.

A equação da análise estática é definida como [14], [15]:

$$
[\mathrm{K}\}\{\mathrm{u}\}=\{\mathrm{F}\}
$$

Em que,

"K" é a matriz de rigidez do sistema gerada automaticamente pelo CREO Simulate com base na geometria e propriedades aplicadas.

"F" é o vetor de forças aplicadas (o qual é especificado).

"u" é o vetor de deslocamentos que são computados pelo CREO Simulate (elementos de força, tensão, reação, etc.). 


\subsection{Arquitetura do Método dos Elementos Finitos}

Em termos de confiabilidade dos resultados obtidos, pela aplicação da técnica FEA, quando comparada aos outros métodos empregados nos dias de hoje, se resume na facilidade de interface com o software de analise. O programa de elementos finitos busca na simplificação de operação, uma maneira de adequar os recursos de equações matemáticas e orientá-las ao objeto de análise [16].

Assim, três etapas contemplam uma programação via FEA, como forma de orientação a lógica computacional, quais sejam [17]:

\section{INPUT $\rightarrow$ SOLVER $\rightarrow$ OUTPUT}

A fase de Input contempla os dados do material e os requisitos do projeto, quais sejam: Geometria, Material, Forças, Restrições e Tipos de elementos. Nesta fase, é de suma importância a representação gráfica da geometria do modelo CAD, com os principais detalhes construtivos, envolvendo a fabricação, montagem e o projeto de fato. Também é importante a entrada dos dados do material a ser utilizado na análise. Faz parte deste tópico: Módulo de elasticidade, Coeficiente de Poisson, Tensão de escoamento, Tensão de Ruptura e Densidade. Além disso, a leitura das condições de contorno pode ser feita nesta fase, como também as condições de carregamento são introduzidas nesta etapa. Neste trabalho utilizou-se a formulação de malhas automáticas encapsuladas no método "P", sendo elevado até o $9^{\circ}$. grau do polinômio interpolador [16]. A Figura 2 ilustra a arquitetura do método FEA, utilizado neste estudo de caso

Figura 2 - Arquitetura computacional do método FEA

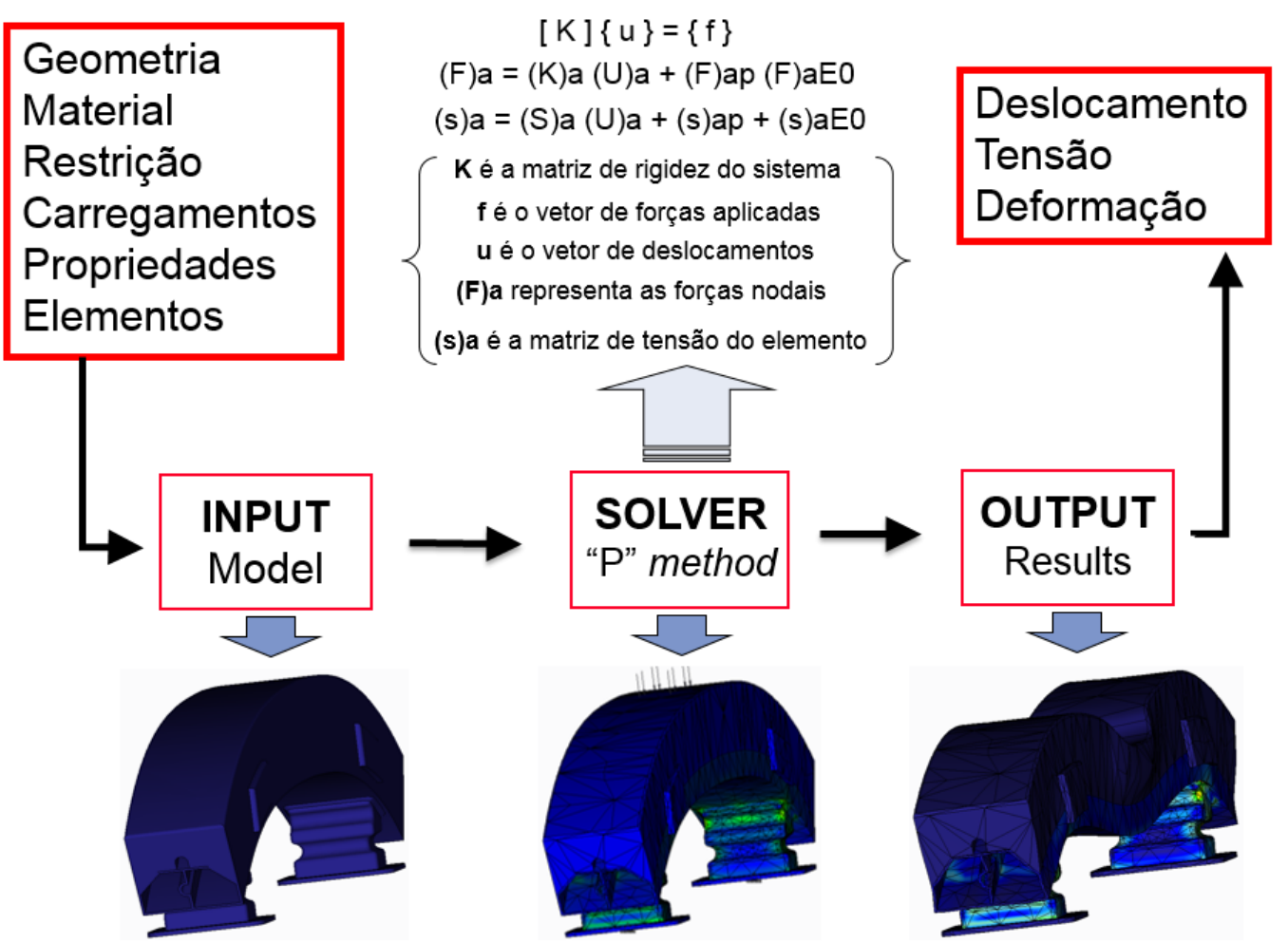

Fonte: Adaptado de [14] 
Na fase de Solver, este tópico diz respeito a formulação do algoritmo que está implementado na rotina de cálculo. Referente ao processamento, existem dois tipos de formações a serem aplicadas: Método "P" e Método "h" [14], [17].

No método " $\mathrm{h}$ ", num acrônimo para "height", discretiza-se a estrutura, formando um reticulado de nós, cuja somatória combinada, forma um elemento. Este elemento tem suas características primarias de sólido de engenharia bem definidas e tecnicamente conhecidas. Assim, quanto mais complexa for a geometria, mais refinamento terá de ser feito, visando a construção de uma malha robusta [14], [17].

No método "P", num acrônimo para polinomial, tem-se as equações baseadas no polinômio interpolador, podendo chegar até o $9^{\circ}$. grau. Este polinômio pode atingir a eliminação de Gauss, Lagrange, entre outros [10], [18]. Neste trabalho, optou-se por usar o método "P" com base no algoritmo do aplicativo CREO 2.0 Simulate, por entender-se que a orientação a objeto e a geometria da peça como um todo, gere uma maior confiabilidade da analise do para-choque veicular.

$\mathrm{Na}$ fase de Output, tem-se o resultado da análise estrutural em diversos formatos, em conformidade com o critério de falha determinado no escopo da analise estrutural. São exemplos de saída de resultados: Tensões, Deformações, Deslocamentos, Gráficos, Diagramas, Temperaturas, Pressões entre outros. A saída gráfica dos resultados, incluindo os aspectos de simulação, dão ao engenheiro analista, a noção exata do que está ocorrendo em termos de realidade aumentada, e convergindo para uma solução computacional robusta, no que se refere as condições de entrada [14], [17].

\subsubsection{Definição do método dos Elementos Finitos}

É uma técnica matemática que consiste em discretizar uma estrutura, modelo matemático tridimensional - em elementos paramétricos ou isoparamétricos conhecidos e conectados por "nós". As propriedades dos Materiais e Elementos são especificados afim de representarem as propriedades físicas do modelo, conforme ilustrado na Figura 3 [17].

Figura 3 - Definição de estrutura, elementos e "nós"

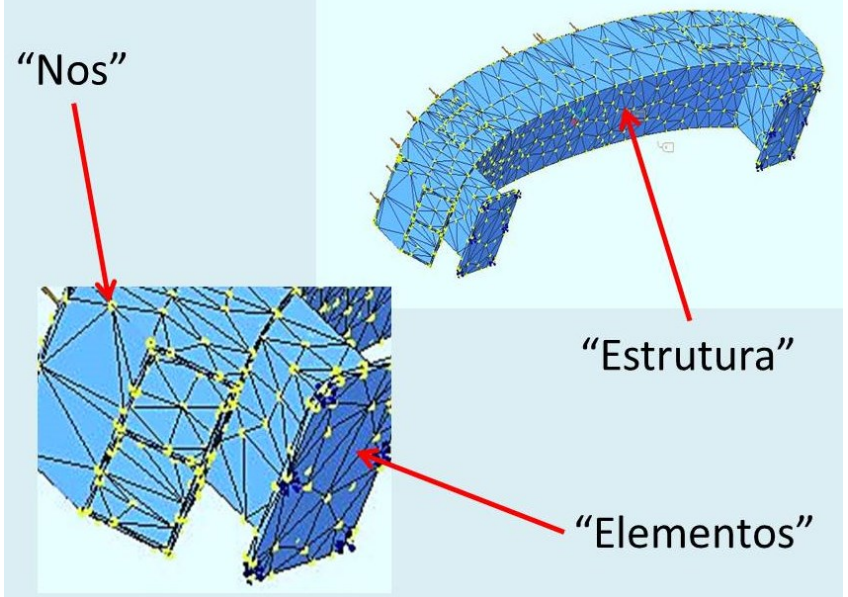

Fonte: Acervo do autor 
O refinamento da malha nos locais de maiores relevâncias, se faz necessário, na medida em que se deseja uma maior acuracidade computacional. Desta forma, há uma tendência da solução da análise, convergir para os resultados do teste prático.

Ao inserir a localização e a intensidade da carga, os nós gerados inicialmente sofrerão uma deformação, ou seja, um deslocamento entre os próprios nós. O solver irá interpretar estes deslocamentos, tratando cada nó como um vetor, e a partir daí, cria-se uma matriz que por sua vez, indica qual a tensão gerada em cada nó que foi deslocado, em função da carga aplicada.

\subsubsection{Entendendo a teoria FEA}

As condições de contorno são especificadas de acordo como o tipo de vinculação do problema, obedecendo as regras da mecânica dos sólidos e da resultante do vetor das forças atuantes. A análise estrutural FEA, deve satisfazer os seguintes requisitos [17]:

- Obter equilíbrio entre: Forças e Momentos;

- Relacionar de forma compatível: Deformação x Deslocamento;

- Relacionar em forma de regra constitutiva: Tensão x Deformação.

As condições acima, são usadas para gerar um sistema de equações, em que os "deslocamentos" são desconhecidos.

Para simular com precisão, acuracidade e eficácia, a complexidade dos fenômenos físicos do mundo real, e por consequência, tratar seus efeitos nos projetos, há que se considerar: Compatibilidade, Relação Forca $x$ Deslocamento e Equilíbrio dos Nós.

- Compatibilidade: Correlação dos deslocamentos dos "nós" externos, fazendo uma solução convergente com a deformação dos elementos;

- Relação "Força/Deslocamento" se estabelece entre: "Elemento end force" e "Elemento end deformation" e também entre as "Forças Nodais e Deslocamentos";

- Equilíbrio imposto entre: Forças Internas e Externas dos Nós.

\subsubsection{Passos para a análise FEA}

Para proceder a análise FEA, algumas etapas são necessárias, para a correta aplicação das condições de contorno. Estas etapas são feitas sequencialmente, de acordo com o tipo de análise, mas geralmente são: Modelamento geométrico, Definir simulação, Modelo de elementos finitos, 
Solver, Avaliar resultados e Otimização [16]. A Figura 4 ilustra um fluxograma topológico, utilizado para o estudo de caso deste trabalho.

Figura 4 - Topologia computacional da análise FEA

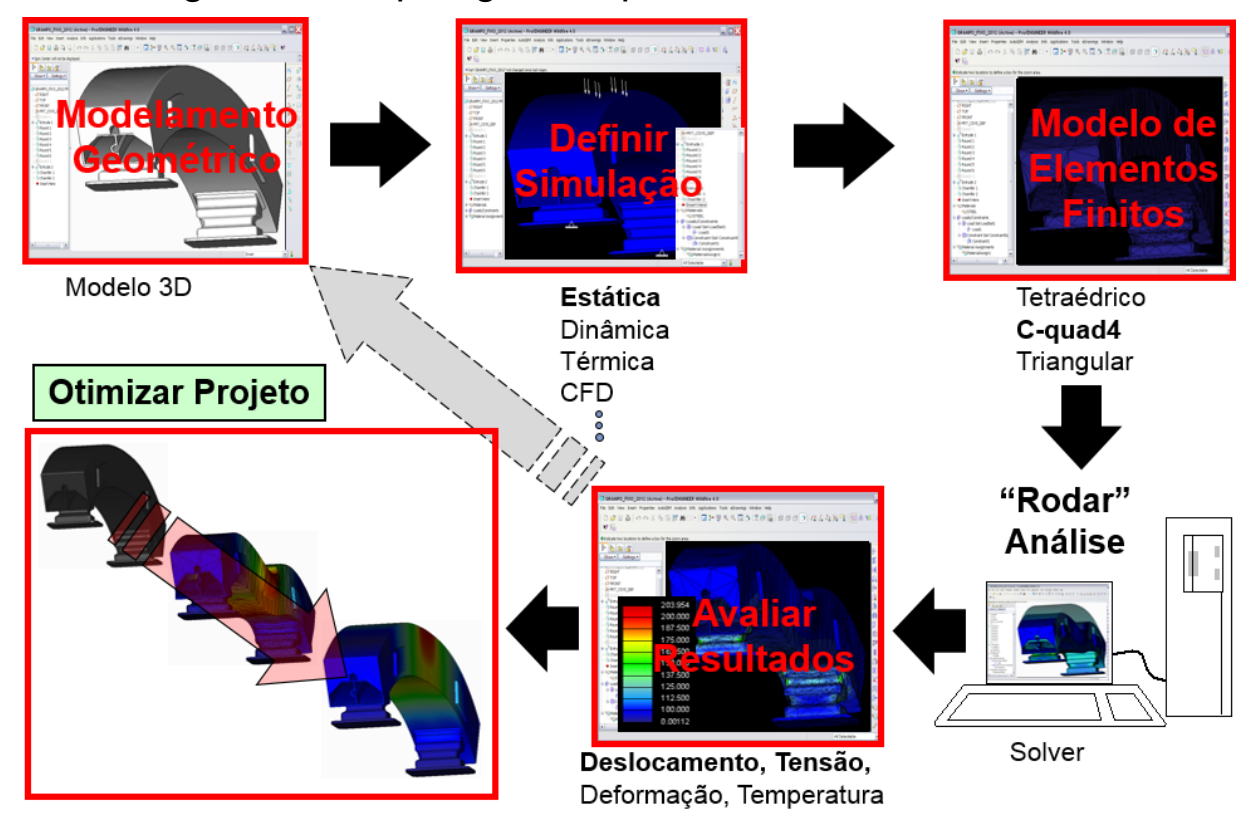

Fonte: Acervo do autor

\section{ESTUDO DE CASO: PARA-CHOQUE VEICULAR}

Este estudo de caso tem por objetivo, prover a simulação computacional de um para-choque veicular dianteiro, e será descrito em dois estados: Modelo Base e Modelo Otimizado.

O termo modelo Base, refere-se a um produto convencional, em que este produto já está desenvolvido e encontra-se atualmente no mercado consumidor. Para este estudo, duas analises de colisão frontal estão previstas: Central e Lateral.

O termo modelo Otimizado, refere-se ao produto base a ser otimizado, em que este produto, será objeto de desenvolvimento e analise computacional. Para este estudo, duas analises de colisão frontal estão previstas: Central e Lateral.

\subsection{Modelo Base}

A princípio foi criado um modelo base de para-choque, fundamentado num produto utilizado em um veículo europeu, e que faz uso da barra de espuma, para absorver o impacto. Todos os componentes foram modelados no software CREO Parametric 2.0, dentro de um ambiente CAD tridimensional.

Para simplificar o estudo e a simulação do modelo virtual, alguns detalhes foram suprimidos dos modelos, como rebaixos na espuma para encaixe da carenagem, e furos de fixação do crash box, na estrutura do veículo. Isto se deve ao fato de que estes detalhes, não exercem influência significativa, na função do para-choque, nem tampouco, interferem nos resultados das simulações. 
A Figura 5 denota os dois modelos CAD de para-choques: (A) Modelo Base e (B) Modelo Otimizado, utilizados neste trabalho.

Figura 5 - Modelos matemáticos CAD de para-choques
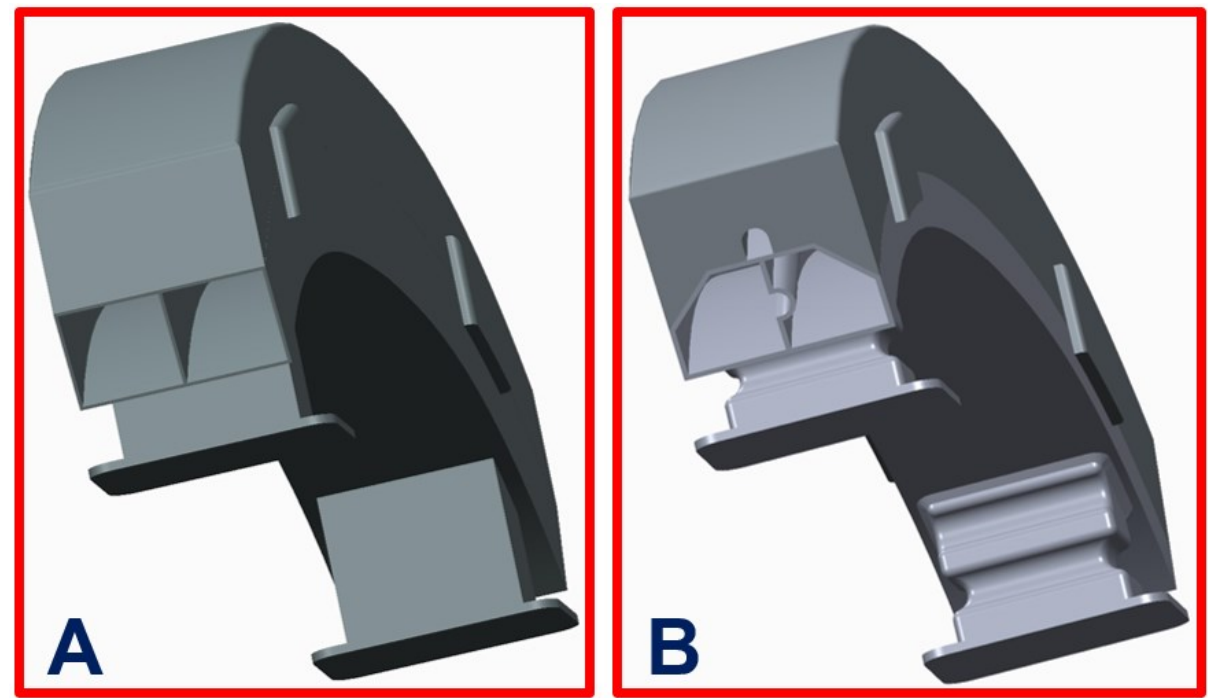

Fonte: Acervo do autor

Depois de concluir a vetorização do modelo matemático, equacionar e calcular a força de impacto, iniciou-se o processo de simulação do modelo base no software CREO Simulate 2.0.

O primeiro passo da simulação foi definir e inserir as condições de contorno, que envolvem o modelo virtual, em outras palavras, inserir e definir o grau de liberdade de cada componente, o contato que cada parte exerce sobre a outra, a localização e a intensidades das forças, que atuam sobre o modelo.

Para um estudo mais elaborado, definiu-se duas diferentes condições de contorno, em que na primeira, a força de impacto age na região centro-frontal (Figura - 6 A) do para-choque, e na outra, com a força agindo na região lateralfrontal (Figura - 6 B), porém ambas com o mesmo grau de liberdade.

Figura 6 - Modelos matemáticos CAD de para-choques
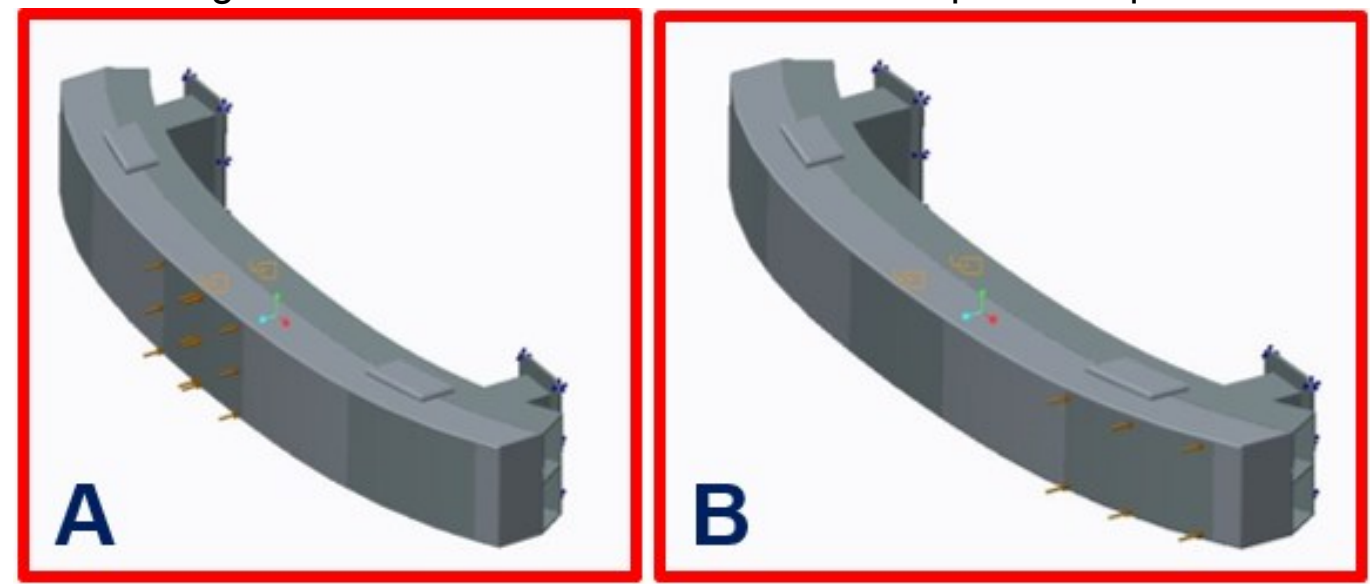

Fonte: Acervo do autor 
Com as condições de contorno já definidas, o próximo passo foi definir e criar a malha, onde esta é responsável por envolver o modelo, e servir de base para o solver realizar os cálculos estruturais (Figura 7).

Figura 7 - Malha padrão

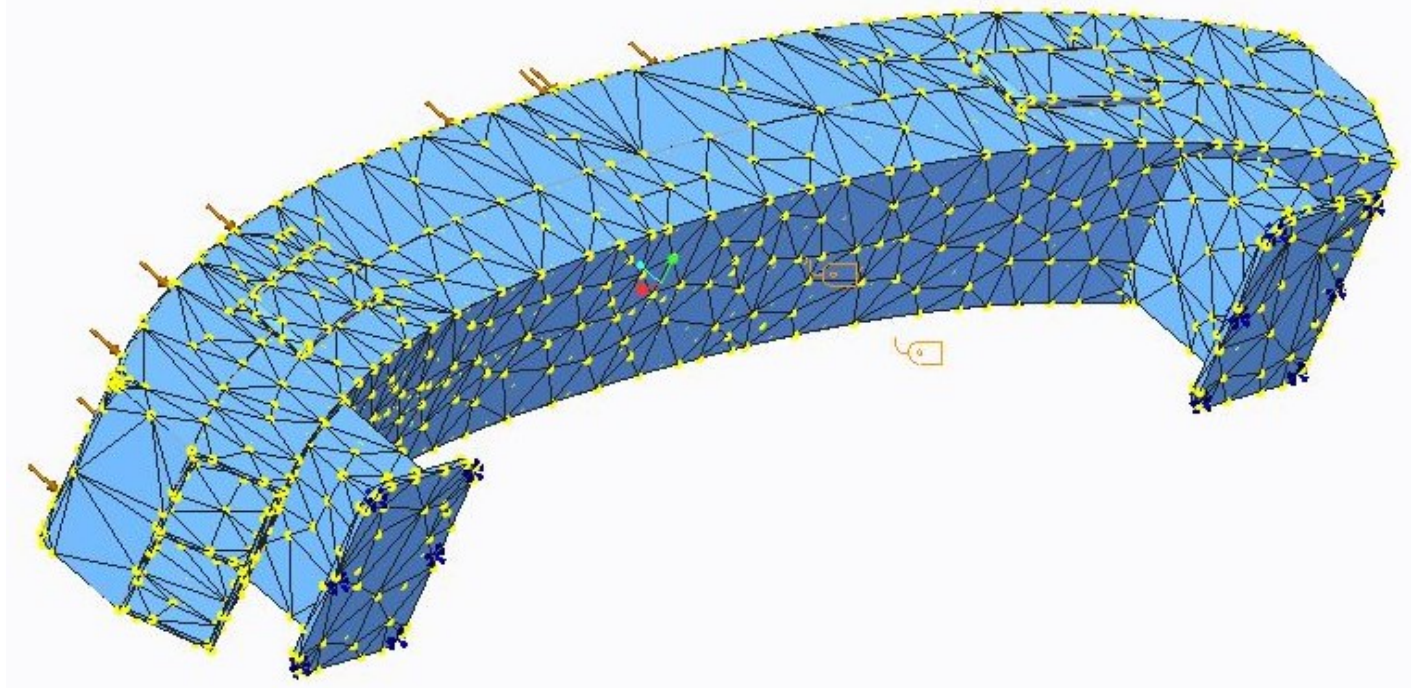

Fonte: Acervo do autor

Depois de definidas todas as condições de contorno e a configuração da malha, para o modelo matemático, a próxima etapa foi a configuração do solver, para a condição de Multiple-Pass, com o grau 9 de polinômio e convergência de 5\%, para o algoritmo interpolador da função polinomial.

\subsubsection{Analise Central}

Logo após configurar o solver, inicializou-se o processo de analise computacional do modelo base, onde foi feito o calculo da analise estrutural, aplicando as condições de contorno centro-frontal. Após a finalização dos cálculos, o solver representou os resultados graficamente, indicando no modelo matemático os deslocamentos ( $\Delta \mathrm{l}$ ) (Figura 8) e as tensões $(\sigma)$ (Figura - 9). A Figura 8 mostra um deslocamento de $1.2 \mathrm{~mm}$, sendo o modelo submetido a uma força de impacto de $1183.5 \mathrm{~kg}$ na região central.

Figura 8 - Deslocamento $(\mathrm{mm})$, modelo base centro-frontal

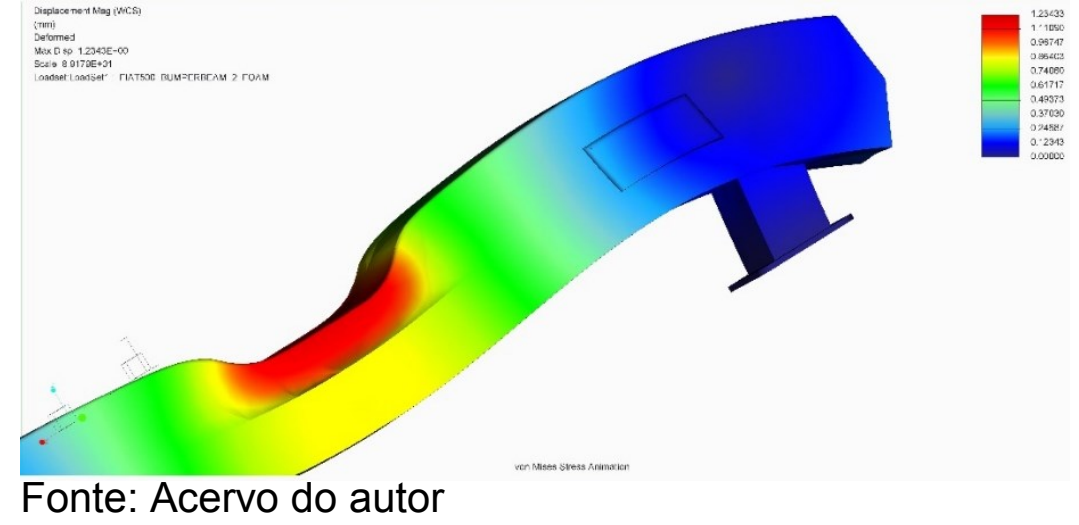


A Figura 9 mostra uma tensão máxima de $184.9 \mathrm{MPa}$, porém, esta tensão aparece somente em alguns pontos específicos, sendo que a tensão predominante, - tensão que age em maior quantidade por área relevante - foi de $50 \mathrm{MPa}$.

Figura 9 - Tensões (Mpa), modelo base centro-frontal

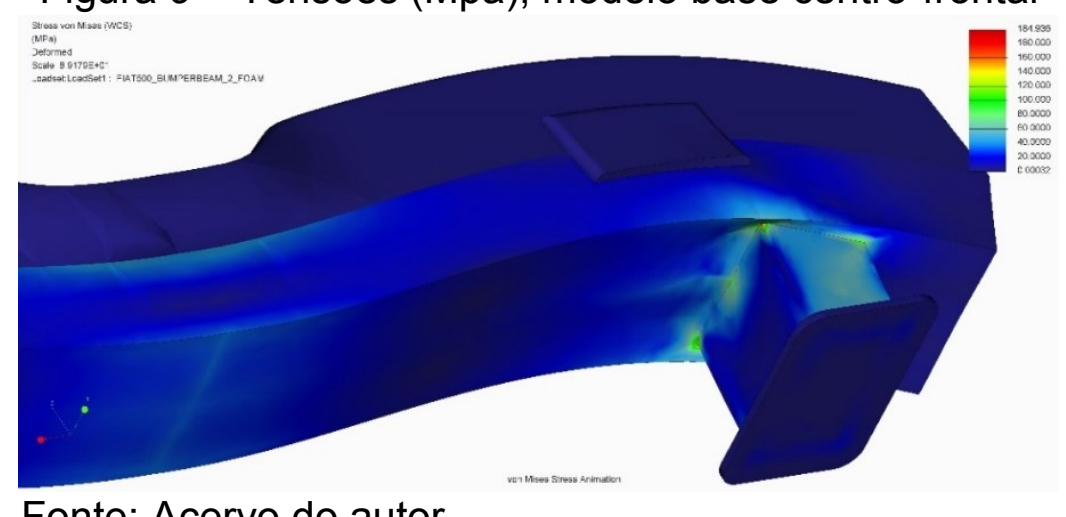

Fonte: Acervo do autor

Para uma melhor análise do modelo, também foi gerada uma tomografia virtual, somente voltada aos aspectos de tensões de von Mises (Figura 10).

Figura 10 - Tensões (MPa), modelo base centro-frontal (tomografia virtual)

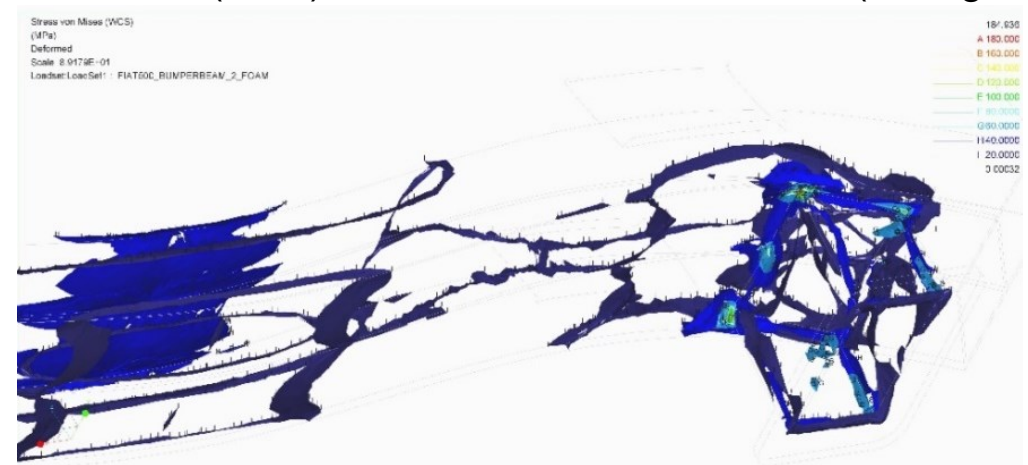

Fonte: Acervo do autor

\subsubsection{Analise Lateral}

O próximo passo foi fazer outra analise computacional, desta vez aplicando as condições de contorno lateral-frontal, em que foram obtidos os resultados de deslocamento (Figura 11) e tensões (Figura 12). A Figura 11 mostra um deslocamento de $0.62 \mathrm{~mm}$, sendo o modelo submetido a uma força de impacto de $1183.5 \mathrm{~kg}$ aplicada na área lateral.

Figura 11 - Deslocamento $(\mathrm{mm})$, modelo base lateral-frontal
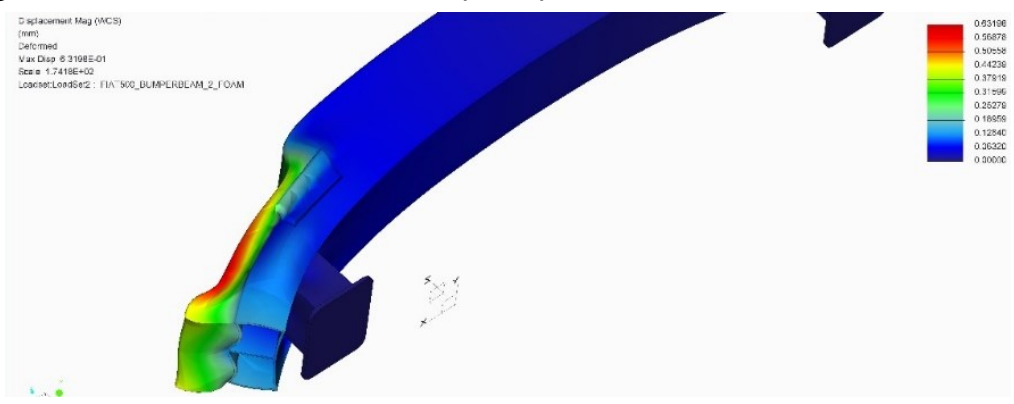
A Figura 12 mostra uma tensão máxima de $192 \mathrm{MPa}$, e novamente essa tensão aparece somente em alguns pontos específicos, sendo que a tensão predominante, nesta condição de contorno foi de $40 \mathrm{MPa}$.

Figura 12 - Tensões (MPa), modelo base lateral-frontal
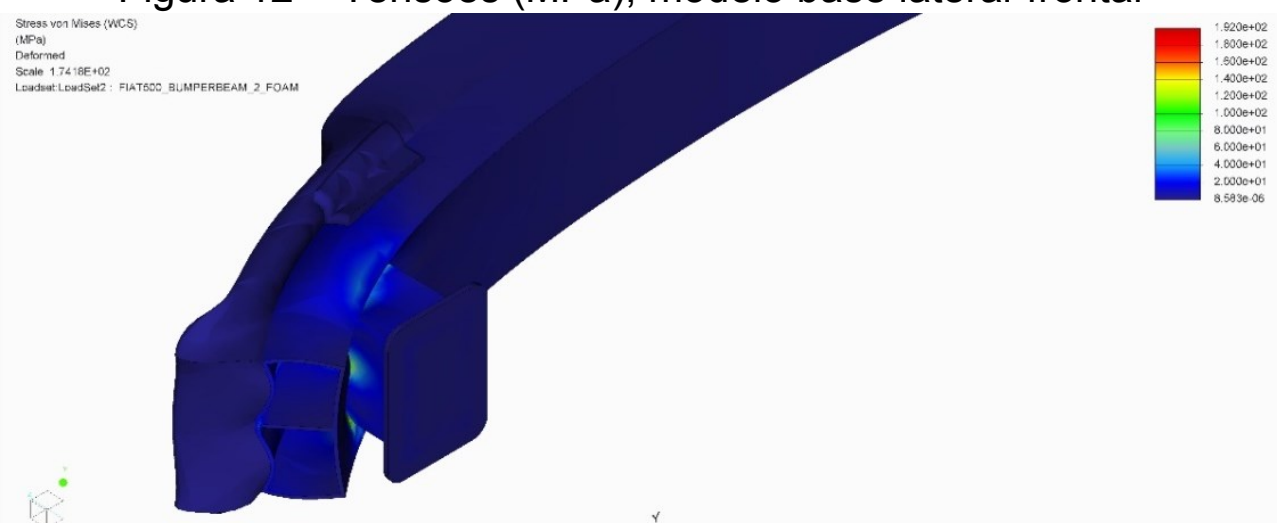

Fonte: Acervo do autor

Uma análise tomográfica também foi gerada, aplicando os aspectos de von Mises, para um melhor diagnóstico do modelo (Figura 13).

Figura 13 - Tensões (MPa), modelo base lateral-frontal (tomografia virtual)

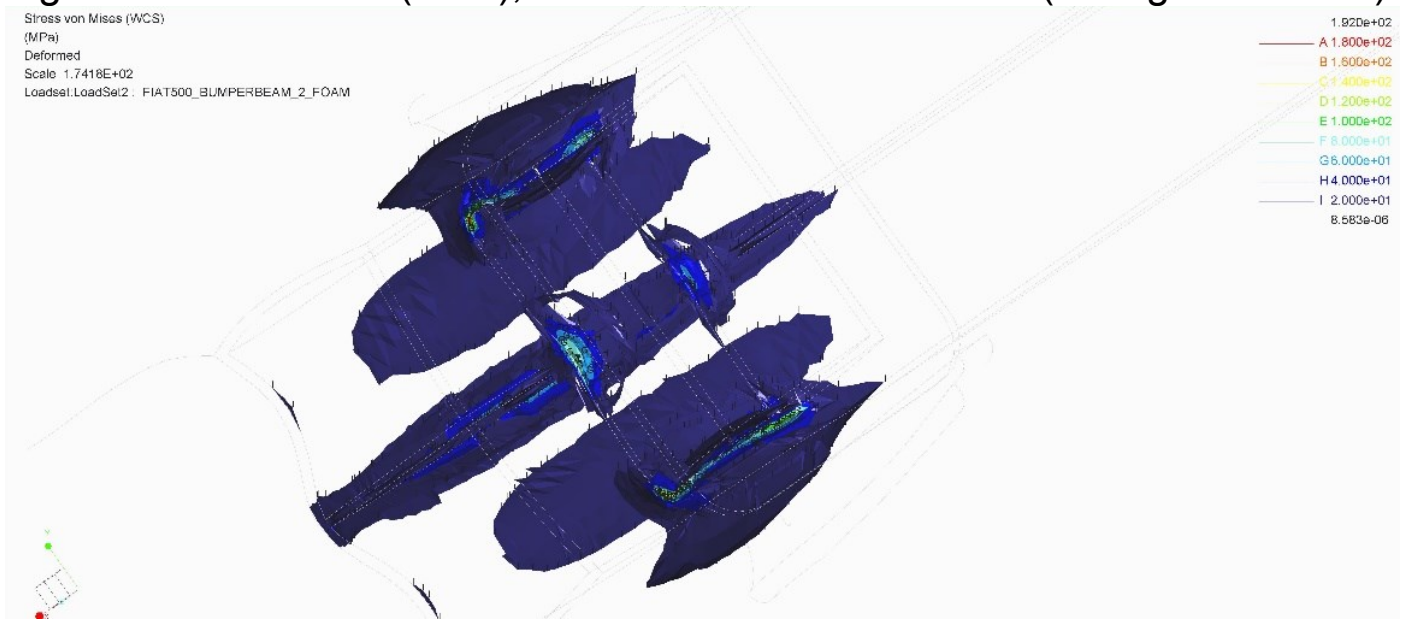

Fonte: Acervo do autor

\subsection{Modelo Otimizado}

A partir dos resultados obtidos anteriormente, foram feitos outros modelos e análises computacionais, considerando as mesmas condições de contorno, e correlacionando-os com o modelo base. Buscou-se então a melhor otimização geométrica que satisfizesse os objetivos inicialmente propostos.

Ao final, obtive-se um modelo que apresentou melhorias consideráveis na absorção do impacto, em ambas as condições de contorno: Central e Lateral.

Além da melhora significativa na absorção do impacto, o modelo geometricamente otimizado, apresentou uma redução volumétrica nas duas peças 
do conjunto, sendo que a espuma obteve uma redução de $810913 \mathrm{~mm}^{3}$, e o parachoque uma redução de $55520 \mathrm{~mm}^{3}$.

As Figuras 14 e 15, ilustram estas características referentes ao modelo base e modelo otimizado, respectivamente.

Figura 14 - Volume modelo base

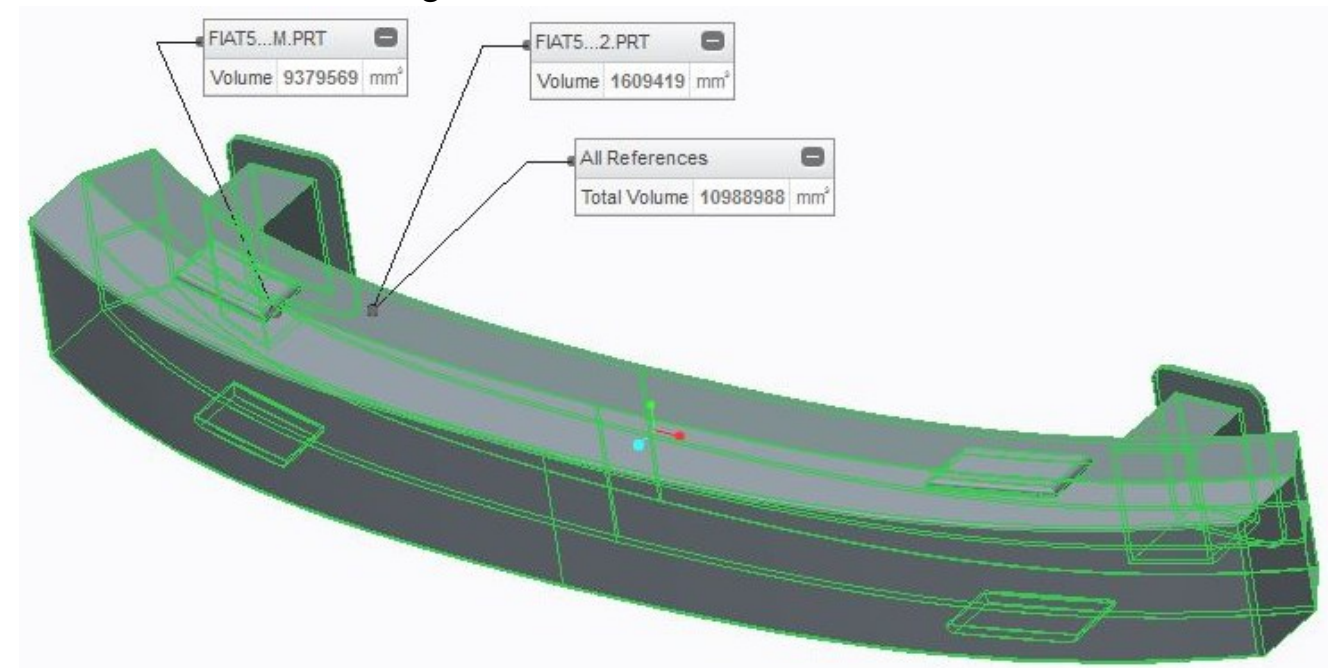

Fonte: Acervo do autor

Figura 15 - Volume modelo otimizado

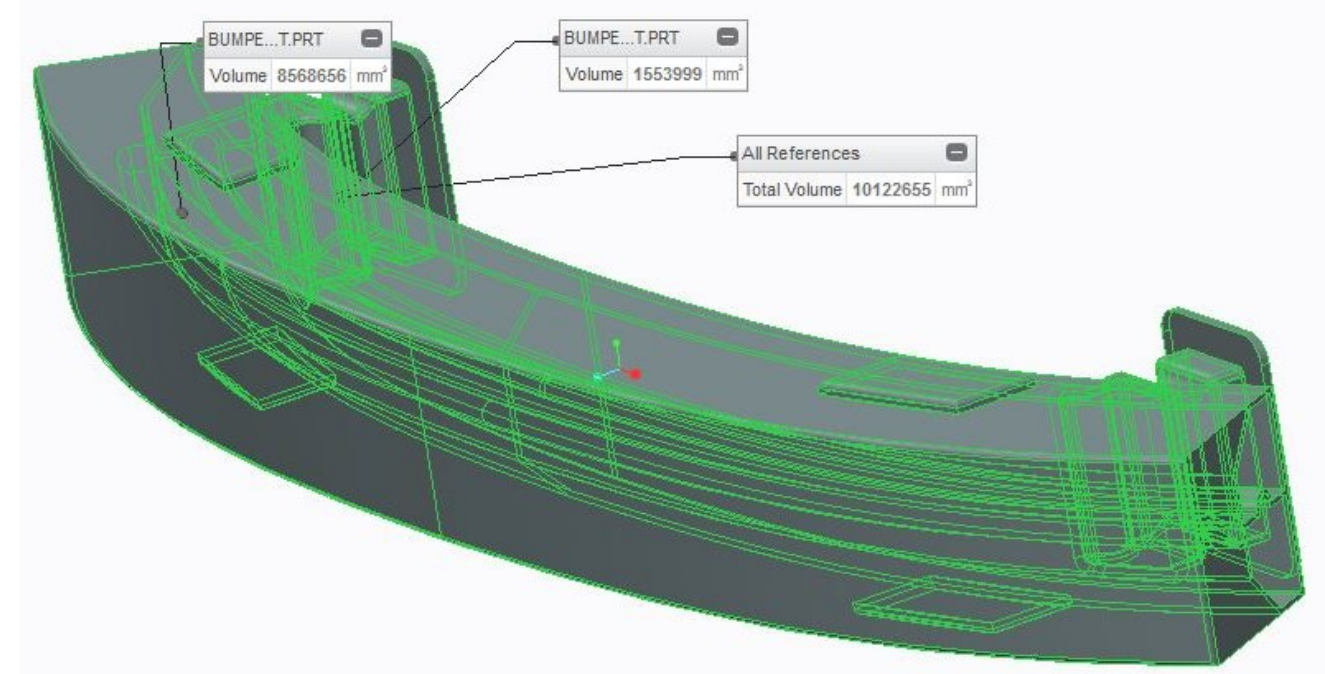

Fonte: Acervo do autor

\subsubsection{Analise Central}

O modelo otimizado representou uma melhor distribuição da tensão e uma deformação maior que a do modelo base. Estas características refletem os objetivos científicos deste trabalho, pois desta forma, devido ao espalhamento das tensões, houve também uma deformação que favorece a absorção do impacto. As Figuras 16, 17, 18 e 19, ilustram as características de Deslocamento $(\mathrm{mm})$, Deslocamento $(\mathrm{mm})$ tomográfico, tensões $(\mathrm{MPa})$ e 
tensões (Mpa) tomográfica. A tomografia virtual evidencia as curvas de iso surfaces, do deslocamento e das tensões.

Conforme mostra a Figura 16, o deslocamento máximo obtido a partir do modelo otimizado, com as condições de contorno centro-frontal, foi de 1.752 $\mathrm{mm}$, significando um aumento de aproximadamente $46 \%$, em relação ao deslocamento máximo do modelo base.

Já a Figura 17 ilustra o deslocamento $(\mathrm{mm})$, evidenciando as curvas de iso surfaces, caracterizando uma tomografia virtual.

Figura 16 - Deslocamento (mm), modelo otimizado centro-frontal

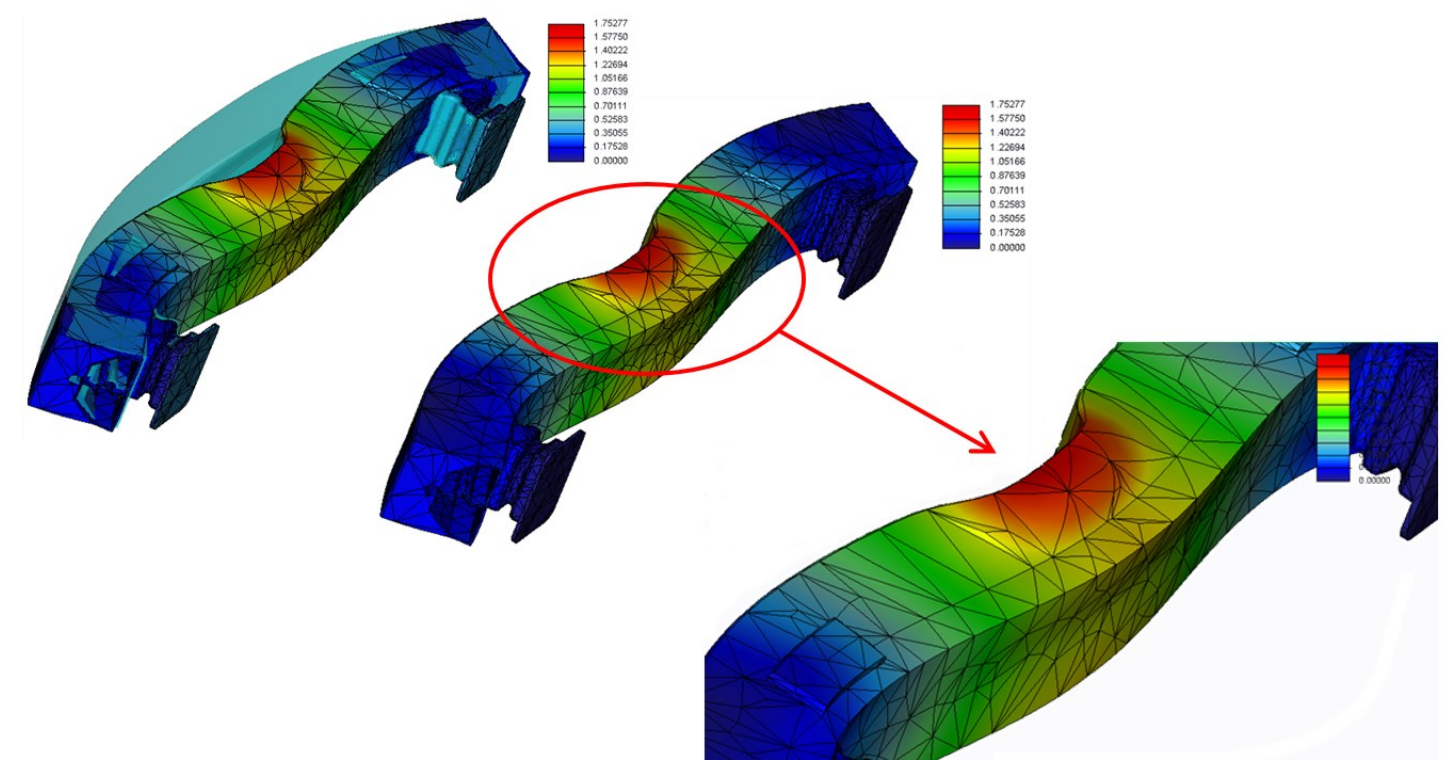

Fonte: Acervo do autor

Figura 17 - Deslocamento (mm), modelo otimizado centro-frontal (tomografia)

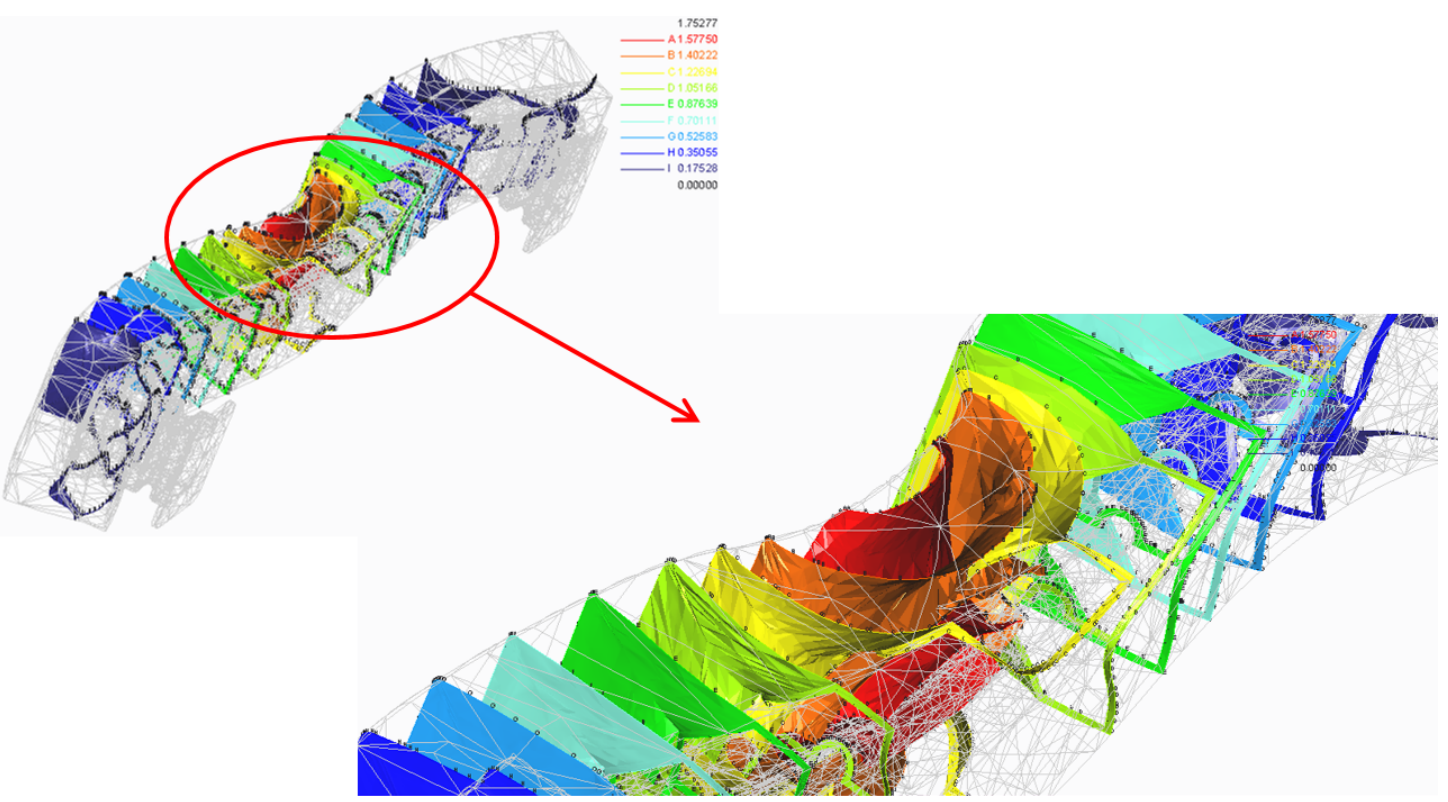

Fonte: Acervo do autor 
A Figura 18 mostra a representação gráfica das tensões. A tensão máxima obtida foi de $203.95 \mathrm{MPa}$ (aumento de aproximadamente 10\% em relação ao modelo base), e ainda continuou distribuída em somente alguns pontos específicos, porém, nota-se uma melhor propagação ao seu redor, proporcionando uma melhor distribuição de tensão. A tensão predominante passou de $50 \mathrm{MPa}$ para $70 \mathrm{MPa}$, representando um aumento de aproximadamente $40 \%$.

Figura 18 - Tensões (Mpa), modelo otimizado centro-frontal

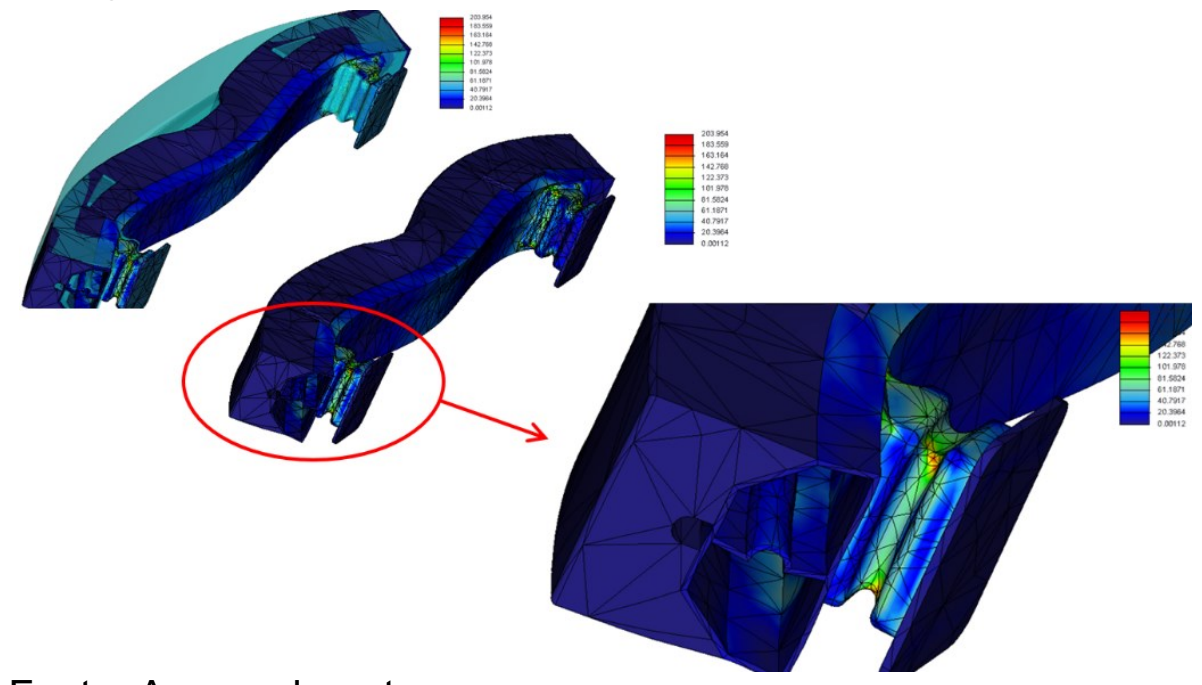

Fonte: Acervo do autor

A análise tomográfica virtual das tensões de von Mises, proporciona uma melhor visualização da melhoria realizada, em que nota-se também uma maior distribuição interna de tensões (Figura 19).

Figura 19 - Tensões (Mpa), modelo otimizado centro-frontal (tomografia)

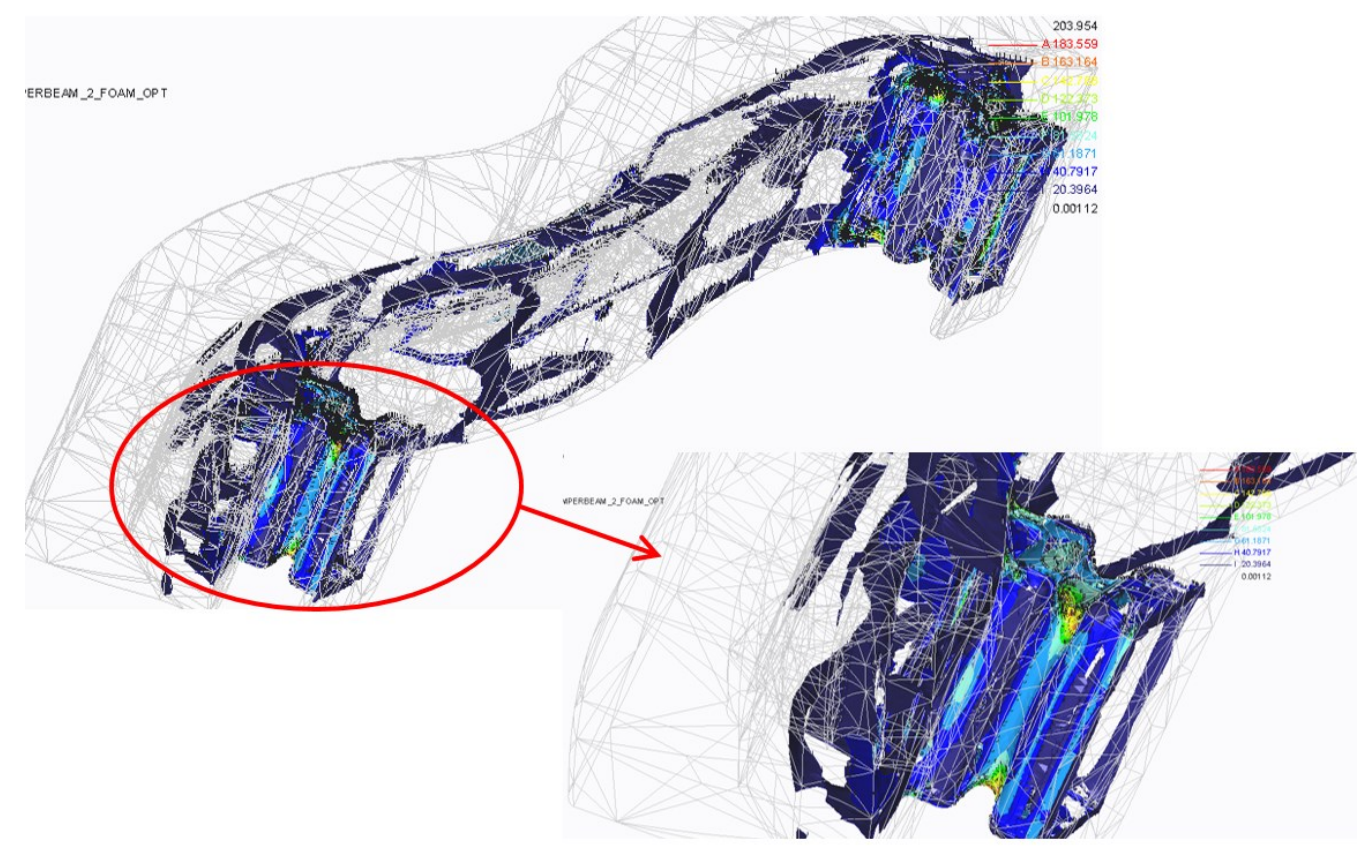

Fonte: Acervo do autor 


\subsubsection{Analise Lateral}

Nesta condição de contorno, o modelo otimizado obteve as mesmas respostas, representando uma melhor distribuição da tensão, e uma deformação maior que a do modelo base, (Figuras 20, 21, 22 e 23).

As Figuras 20 e 21, mostram um deslocamento máximo sob as condições de contorno lateral-frontal de $0.95 \mathrm{~mm}$, representando um aumento de pouco mais de $50 \%$, se comparado com o modelo base. A Figura 21 ilustra a imagem da tomografia virtual representada pelo deslocamento $(\mathrm{mm})$.

Figura 20 - Deslocamento (mm), modelo otimizado lateral-frontal
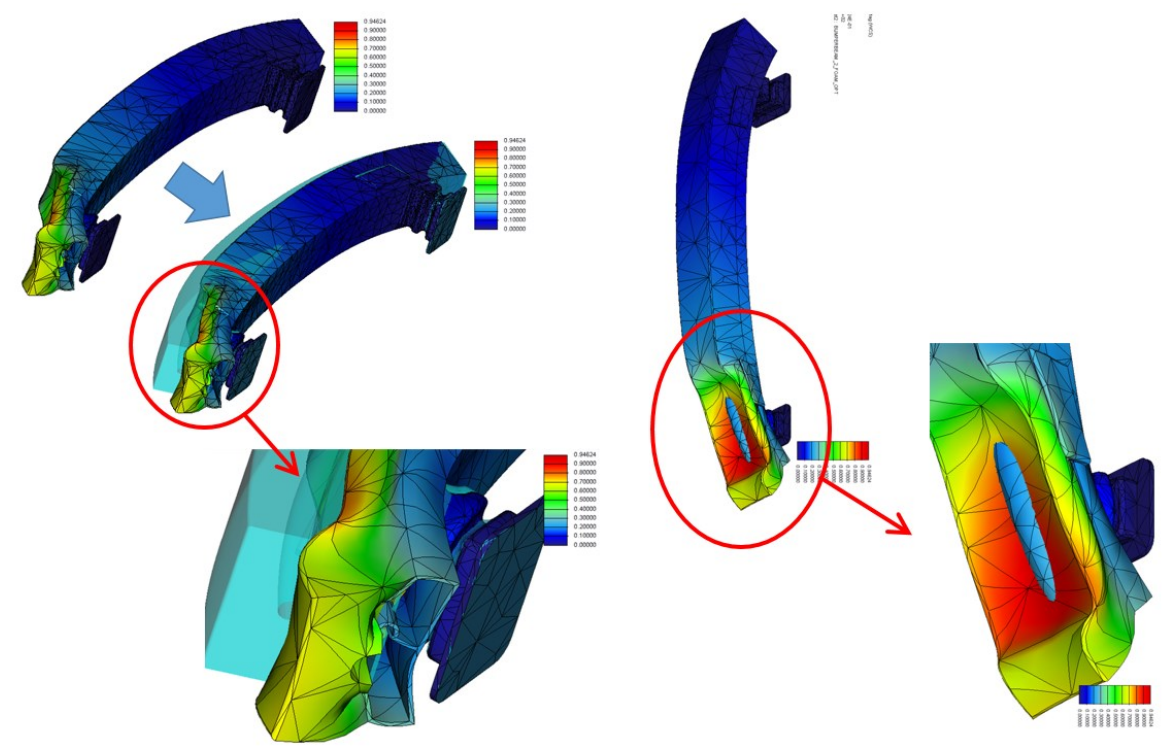

Fonte: Acervo do autor

Figura 21 - Deslocamento (mm), modelo otimizado lateral-frontal (tomografia)
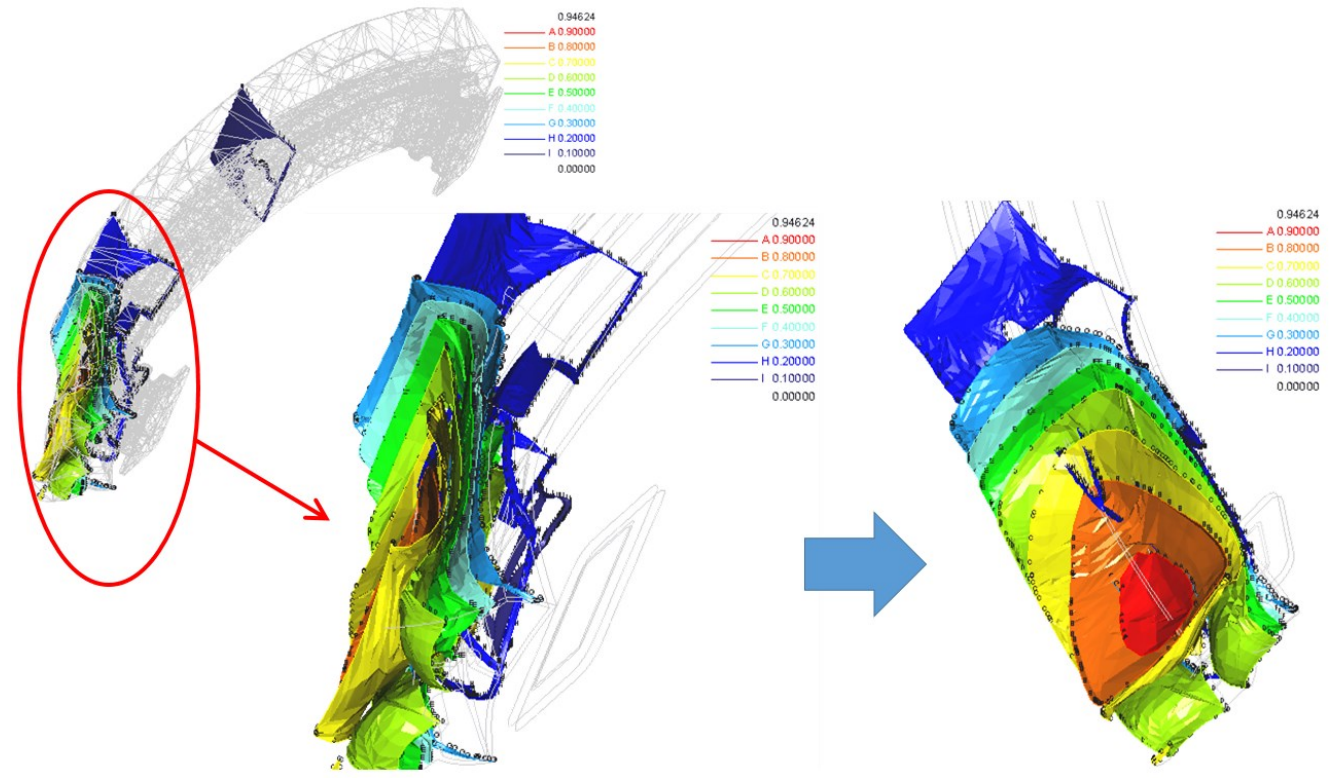

Fonte: Acervo do autor 
Representando graficamente as tensões, a Figura 22 denota que a tensão máxima de $224 \mathrm{Mpa}$ ( $16 \%$ de aumento), também continuou distribuída em pontos específicos, e também pode-se visualizar uma melhor distribuição ao seu redor. A tensão predominante na área passou a ser de $65 \mathrm{MPa}$, proporcionando um aumento significativo de $60 \%$, quando comparado com a tensão de $40 \mathrm{MPa}$ do modelo base.

Figura 22 - Tensões (Mpa), modelo otimizado lateral-frontal

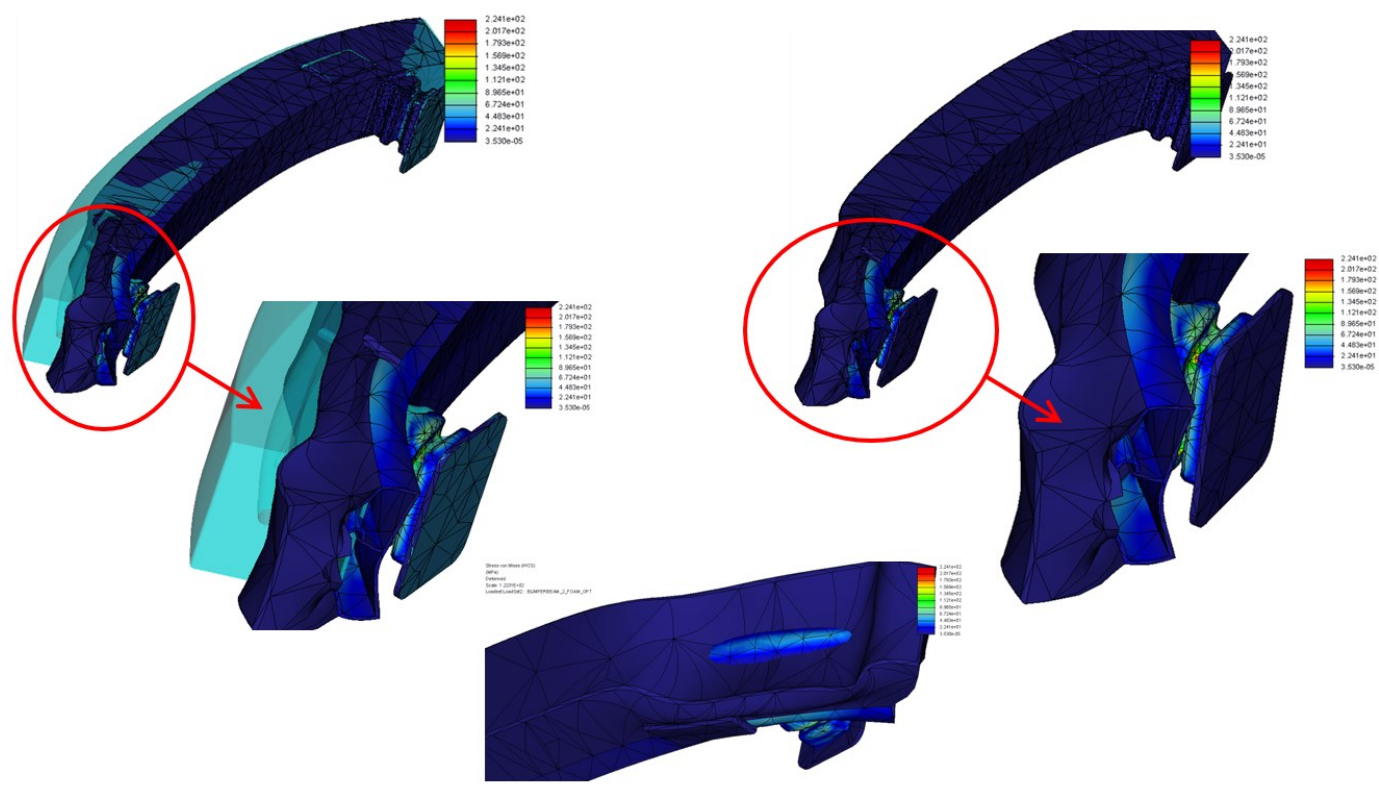

Fonte: Acervo do autor

A tomografia virtual da Figura 23, descreve melhor este aumento, mostrando a distribuição interna das tensões.

Figura 23 - Tensões (MPa), modelo otimizado lateral-frontal (tomografia)

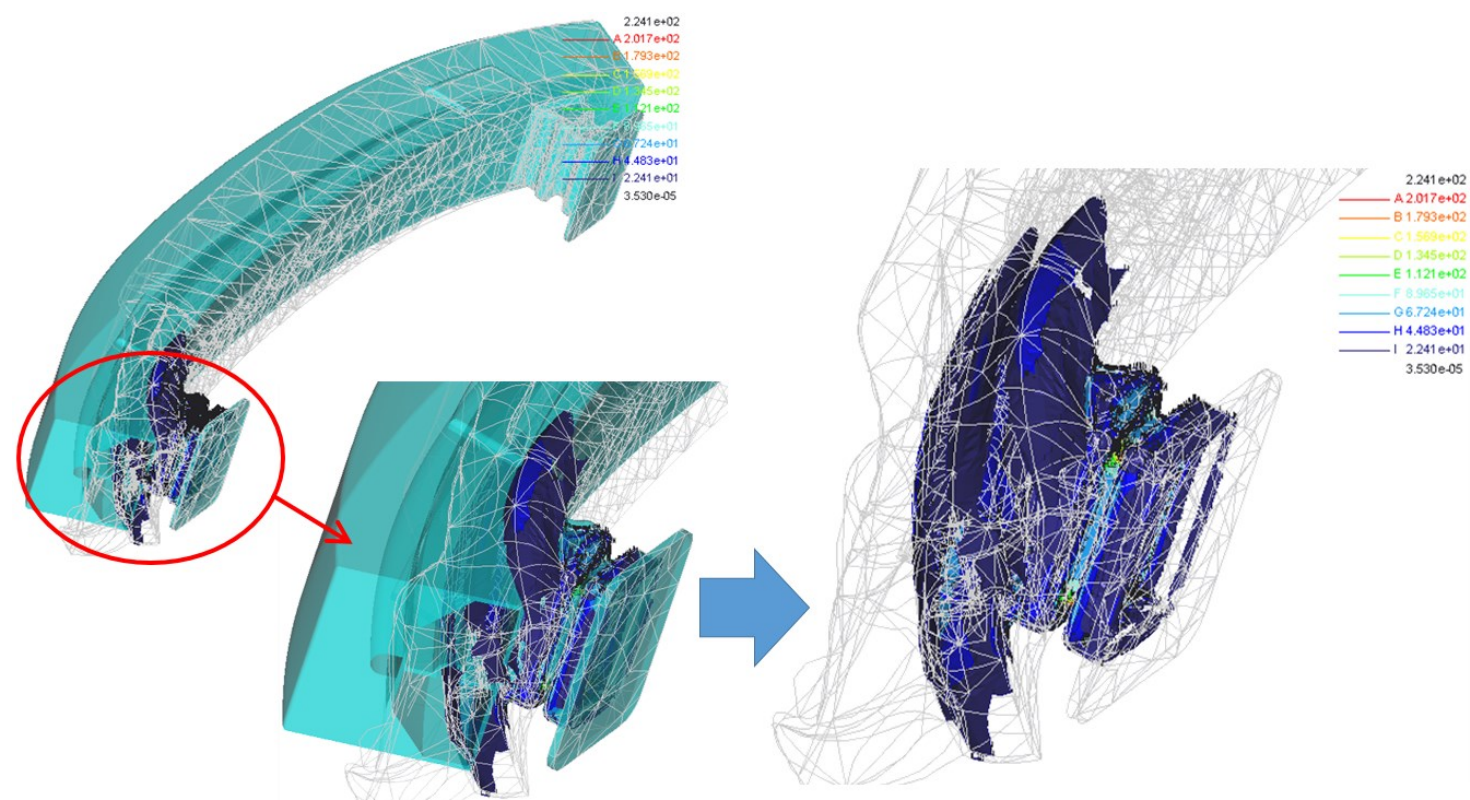

Fonte: Acervo do autor 


\subsection{Bulk Data}

Foram realizadas analises estruturais lineares no para-choque, para obtenção de resultados de tensões e deslocamentos, sob uma força decorrente do impacto "carro $x$ pedestre", simulando as condições reais das reações estruturais.

Para a analise, utilizou-se um processador Intel Core i5-3210M, 2.50GHz, 64bits, 6GB RAM e disco rígido de 1TB, além de:

Para o modelo base:

\begin{tabular}{|l|c|c|c|c|}
\hline & \multicolumn{2}{|c|}{ Modelo Base } & \multicolumn{2}{c|}{ Modelo Otimizado } \\
\hline & Central & Lateral & Central & Lateral \\
\hline Tempo Processamento (s) & 193.86 & 240.60 & 350.36 & 203.70 \\
\hline Espaço disco (MB) & 512 & 512 & 512 & 512 \\
\hline $\mathrm{N}^{\circ}$ Elementos Tetra & 1896 & 1896 & 4350 & 4350 \\
\hline $\mathrm{N}^{\circ}$ Elementos Edges & 9957 & 9957 & 22537 & 22537 \\
\hline $\mathrm{N}^{\circ}$ Elementos Faces & 14505 & 14505 & 32278 & 32278 \\
\hline
\end{tabular}

Quanto ás condições de contorno, foi utilizado um modelo matemático 3D gerado no ambiente CAD CREO 2.0, para atender as condições de contorno iniciais. Posteriormente, adentrou-se ao módulo CAE que está encapsulado no aplicativo CREO, denominado agora de CREO Simulate.

\subsection{Margem de Segurança e Dados dos Materiais}

Para o cálculo da margem de segurança, a seguinte fórmula foi aplicada [18]:

Margem de segurança $=($ Gesc $/ \sigma$ calculado $)-1=\left[{ }^{*} 100 \mathrm{p} / \%\right]$

Com relação aos dados dos materiais empregados nesta análise, a Tabela 1 ilustra as características físicas dos materiais alumínio e espuma expandida.

Tabela 1 - Características físicas dos materiais utilizados

\begin{tabular}{|c|c|c|c|c|c|}
\hline Material & $\begin{array}{c}\mathrm{E} \\
{[\mathrm{GPa}]}\end{array}$ & $v$ & $\begin{array}{c}\rho \\
{[\mathrm{g} / \mathrm{cc}]}\end{array}$ & $\begin{array}{c}\text { Orup } \\
{[\mathrm{MPa}]}\end{array}$ & $\begin{array}{c}\sigma e s c \\
{[\mathrm{MPa}]}\end{array}$ \\
\hline AL-6061 & 69 & 0.33 & 2.70 & 310 & 276 \\
\hline $\begin{array}{c}\text { Espuma } \\
\text { Polímero Exp. }\end{array}$ & 0.075 & 0.45 & 0.101 & 2.50 & - \\
\hline
\end{tabular}

Fonte: Acervo do autor

Em que:

E - módulo de elasticidade

$v$ - coeficiente de Poisson

$\rho$ - densidade

бrup - tensão de ruptura

$\sigma_{\text {esc }}$ - tensão limite de escoamento 


\section{CONCLUSÃO}

Os resultados apontados nas representações gráficas, mostram uma melhora significativa na absorção da força de impacto, além de apresentar uma redução volumétrica. $\mathrm{O}$ modelo geometricamente otimizado, mostra-se menos rígido em comparação ao modelo base, proporcionando um deslocamento médio de $48 \%$ a mais, gerando um aumento da tensão que age sobre o modelo, considerando as mesmas condições de contorno. Este deslocamento gerou tensões máximas de 203.95 e $224 \mathrm{MPa}$, nas condições centro-frontal e lateral-frontal subsequentemente; onde esses valores representam um aumento médio de $13 \%$ se comparado ao modelo base. Uma vez que o limite de escoamento do alumínio AL-6061 é de 276 $\mathrm{MPa}$, pode-se concluir que o resultado da simulação virtual corresponde a uma margem de segurança de $20 \%$, em relação a tensão de escoamento.

Porém, um detalhe bastante relevante, e responsável na melhoria significativa da absorção de impacto, é a melhor distribuição das tensões no modelo virtual otimizado, sendo também evidenciadas internamente através das tomografias virtuais. Essa melhor distribuição, aumentou em média $50 \%$ o valor das tensões predominantes no modelo, o que representa uma maior absorção da força de impacto, sem que ocorra a deformação plástica ou ruptura do material.

Visto isto, conseguiu-se elaborar uma otimização geométrica de um para-choque veicular dianteiro, fazendo com que o mesmo proporcione maior segurança ao pedestre, utilizando os argumentos da mecânica dos sólidos, por meio da técnica FEA. Lembrando que este estudo é voltado apenas ao segmento da segurança do pedestre, sendo que a geometria ideal de um para-choque, deve ser obtida através do estudo correlacionado deste trabalho, e de um estudo de impacto entre dois veículos.

Para trabalhos futuros, aponta-se para uma comprovação prática dos argumentos aqui descritos, como prova de validação da hipótese denotada neste trabalho.

\section{REFERÊNCIAS}

[1] Sminkey, L., More Than 270000 Pedestrians Killed on Roads Each Year, World Health Organization, 2013. Disponível em:

$<$ http://www.who.int/mediacentre/news/notes/2013/make_walking_safe_2013050 2/en/>. Acesso em 04 mar. 2015

[2] GROWTH, General Safety and Pedestrian Safety Stakeholder Meeting, CCAB, Bruxelas, Belgica, 2014. Disponível em: <http://ec.europa.eu/enterprise/newsroom/cf/itemdetail.cfm?item_id=7803>. Acesso em 04mar. 2015

[3] Bartczak, B., Gierczycka-Zbrozek, D., Gronostajski, Z., Polak, S., Tobota, A., The Use of Thin-Walled Sections for Energy Absorbing Components: A Review, Archives of Civil and Mechanical Engineering, v.10, n.4, 2010, pp. 5-19 
[4] ARUP, ARUP: A New Pedestrian Lower Legform Model for LS-DYNA, 2003

[5] Pahl, G., Beitz, W., Feldhusen, J., Grote, K.-H., Projeto na Engenharia, $1^{a}$ ed., Edgard Blücher, São Paulo, 2005

[6] Rozenfeld, H., Forcellini, F.A., Amaral, D.C., Toledo, J.C., Silva, S.L., Alliprandini, D.H., Scalice, R.K., Gestão de Desenvolvimento de Produtos: Uma referência para a Melhoria do Processo, Saraiva, São Paulo, 2011

[7] Ehrlenspiel, K., Kiewert, A., Lindemann, U., Cost-Efficient Design, ASME Press, ISBN 0-7918-0250-7, New York, 2007

[8] Back, N., Ogliari, A., Dias, A., Da Silva, J.C., Projeto Integrado de Produtos: Planejamento, Concepção e Modelagem, ISBN: 9788520422083, Editora Manole, São Paulo, 2008

[9] Camargo, R., Topologia de Projeto Robusto aplicando o método dos Elementos Finitos, Revista Ciência e Tecnologia, v. VII, p. 13-29, 2004

[10] Timoshenko,S.P., Mecânica dos Sólidos Vol. 1/2, Editora LTC, RJ, 1998

[11] Rechnitzer, G., "Design Principles for Underride Guards and Crash Test Results", Notes for SAE Heavy Vehicle Underride Protection TOPTEC, April 1516 1997, Palm Springs, USA, 1997

[12] FEM-UNICAMP, "Projeto Impacto". Disponível em: <http://www.fem.unicamp.br/ impact/forcab.htm>. Acesso em 05mar. 2015

[13] BRASIL, Código de Transito Brasileiro, Art.61, Lei № 9.503, 1997

[14] MacNeal R., Schwendler, W., MSC/NASTRAN for Window Finite Element Modeling, MacNeal Schwendler Corporation, San Diego / California, 1997

[15] Zienkiewicz, O.C., Taylor, R.L., Finite Element Method- Basic Formulation and Linear Problems, Vol.1, McGraw-Hill Co., New York, 1989

[16] Oliveira, E.S., Camargo, R., Analise estrutural via metodologia FEA: Estudo de um macaco automotivo, correlacionando o teste físico de um protótipo em laboratório e a simulação virtual, SIMEA, Bluecher Proceedings, São Paulo, 2014

[17] Alves Filho, A., Elementos Finitos - A Base da Tecnologia CAE, Editora Erica, São Paulo, 2014

[18] Roarke, W.D., Formulas for Stress \& Strain, McGraw-Hill, 2010 